PREPARED FOR THE U.S. DEPARTMENT OF ENERGY, UNDER CONTRACT DE-AC02-76CH03073

PPPL-3932

PPPL-3932

UC-70

Neutral Particle Analyzer Diagnostic on NSTX

by

S.S. Medley and A.L. Roquemore

March 2004

$\left.\stackrel{M}{M}\right|_{\substack{\text { PRInCETON PLASIMA } \\ \text { PHYSICS LABORATORY }}} ^{D}$

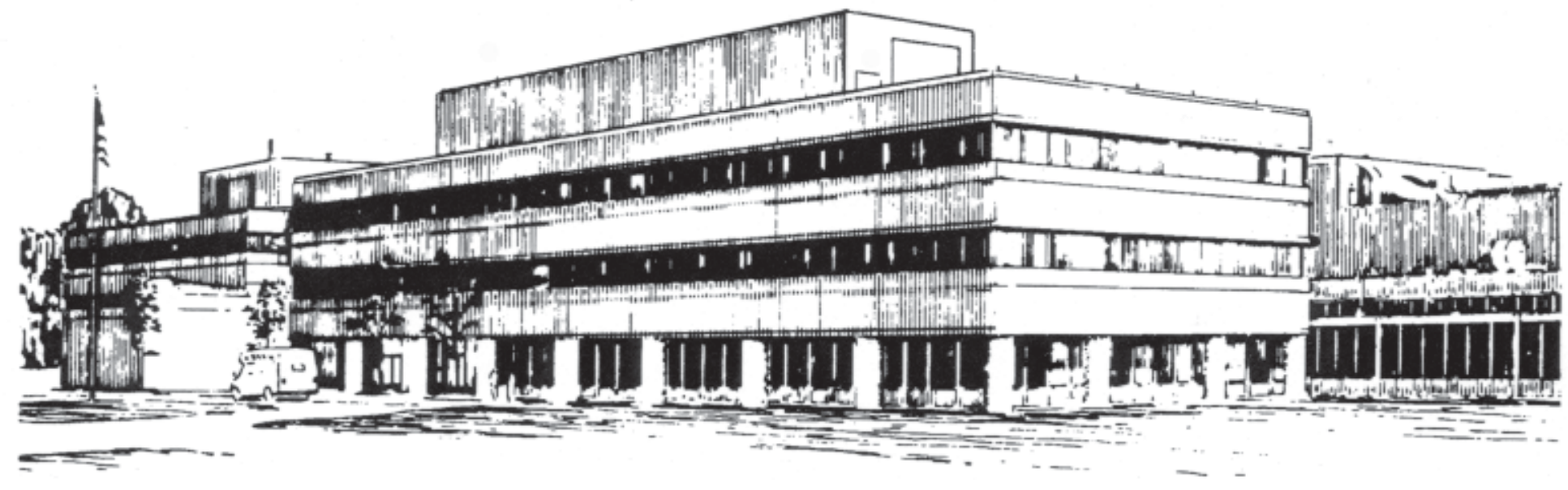

PRINCETON PLASMA PHYSICS LABORATORY PRINCETON UNIVERSITY, PRINCETON, NEW JERSEY 


\section{PPPL Reports Disclaimer}

This report was prepared as an account of work sponsored by an agency of the United States Government. Neither the United States Government nor any agency thereof, nor any of their employees, makes any warranty, express or implied, or assumes any legal liability or responsibility for the accuracy, completeness, or usefulness of any information, apparatus, product, or process disclosed, or represents that its use would not infringe privately owned rights. Reference herein to any specific commercial product, process, or service by trade name, trademark, manufacturer, or otherwise, does not necessarily constitute or imply its endorsement, recommendation, or favoring by the United States Government or any agency thereof. The views and opinions of authors expressed herein do not necessarily state or reflect those of the United States Government or any agency thereof.

\section{Availability}

This report is posted on the U.S. Department of Energy's Princeton Plasma Physics Laboratory Publications and Reports web site in Fiscal Year 2004. The home page for PPPL Reports and Publications is: http://www.pppl.gov/pub_report/

DOE and DOE Contractors can obtain copies of this report from:

U.S. Department of Energy

Office of Scientific and Technical Information

DOE Technical Information Services (DTIS)

P.O. Box 62

Oak Ridge, TN 37831

Telephone: (865) 576-8401

Fax: (865) 576-5728

Email: reports@adonis.osti.gov

This report is available to the general public from:

National Technical Information Service

U.S. Department of Commerce

5285 Port Royal Road

Springfield, VA 22161

Telephone: $1-800-553-6847$ or

(703) $605-6000$

Fax: (703) 321-8547

Internet: http://www.ntis.gov/ordering.htm 


\title{
Neutral Particle Analyzer Diagnostic on NSTX*
}

\author{
S. S. Medley and A. L. Roquemore \\ Princeton Plasma Physics Laboratory, Princeton, New Jersey, 08543, USA
}

Email: medley@pppl.gov

\begin{abstract}
The Neutral Particle Analyzer (NPA) diagnostic on the National Spherical Torus Experiment (NSTX) utilizes a PPPL-designed EIIB spectrometer that measures the energy spectra of minority hydrogen and bulk deuterium species simultaneously with 39 energy channels per mass specie and a time resolution of $1 \mathrm{~ms}$. The calibrated energy range is $E=0.5-150 \mathrm{keV}$ and the energy resolution varies from $\triangle E / E=3-7 \%$ over the surface of the microchannel plate detector. The NPA measures Maxwellian spectra of residual hydrogen to obtain ion temperatures and measures the energetic ion spectra produced by injection of up to $100 \mathrm{keV}$ deuterium neutral beams into a deuterium plasma. The NPA views across the co-injection paths of the three neutral beam sources on NSTX which localizes the measured charge exchange effux to the intersection region. The incorporation of horizontal scanning for the NPA over a sightline tangency range of $R_{\text {tan }}=125 \mathrm{~cm}$ to $R_{\text {tan }}=-75 \mathrm{~cm}$ has enabled measurement of the anisotropic energy distribution of the beam ions. Vertical scanning allows measurements to be made from the horizontal midplane through an angle of 26 degrees downward. A description of the NPA diagnostic on NSTX will be presented along with illustrations of measurement capability.

*This work was supported at PPPL by DOE Contract DE-AC02-76CHO3073.
\end{abstract}




\section{Introduction}

The National Spherical Torus Experiment (NSTX) [1] is a midsize low aspect ratio fusion research facility with auxiliary heating from Neutral Beam Injection (NBI) and High Harmonic Fast Wave (HHFW) launch. Typical NSTX parameters are major radius $R_{0}=0.85-0.9 \mathrm{~m}$, minor radius $a=0.67 \mathrm{~m}$ resulting in an aspect ratio of $A=R_{d} / a \sim 1.3$, plasma current $I_{\mathrm{p}}=0.3-1.5 \mathrm{MA}$ and toroidal field $B_{\mathrm{T}}=0.3$ - 0.6 T. Three co-directed deuterium neutral beam sources have injected power up to $P_{\mathrm{NB}}=7 \mathrm{MW}$ at full neutral energies up to $E_{\mathrm{b}} \leq 100 \mathrm{keV}$. HHFW heating at $30 \mathrm{MHz}$ has delivered up to $P_{\mathrm{RF}} \sim 6 \mathrm{MW}$ to deuterium and helium plasmas.

Determining the attractiveness of the spherical torus concept [2] in the areas of high- $\square$ stability, confinement, non-inductive current drive and divertor physics for pulse lengths much longer than the energy confinement time is the mission of the NSTX device. The performance milestones that were achieved to date in NSTX have been reported elsewhere [3-6]. H-modes triggered by NBI heating are routinely obtained in NSTX and have become a standard operational scenario [7]. L-H transitions triggered by NBI heating have been obtained over a wide parameter range in $I_{p}, B_{T}$ and $n_{e}$ in either lower-single-null or double-null diverted discharges with elongation $\square \leq 2.4$, triangularity $\square \leq 0.8$ and plasma pulse length up to $1 \mathrm{~s}$. To date NSTX has achieved, non-simultaneously, stored energies up to $0.39 \mathrm{MJ}$, energy confinement times $\square_{\mathrm{E}}<0.12 \mathrm{~s}$ and $\square_{\mathrm{T}} \leq 35 \%$ [3]; $\square_{T}=\left\langle p>/\left(B_{0}{ }^{2} / 2 \square_{0}\right)\right.$ where $\left\langle p>\right.$ is the volume averaged total pressure and $B_{0}$ is the vacuum magnetic field at $R_{0}$.

This paper presents a description of the NPA diagnostic on NSTX along with certain performance characteristics. Illustrations of thermal spectra to extract ion temperature measurements and neutral beam energetic ion distributions are presented.

S. S. Medley, et al., Contributed paper to the $15^{\text {th }}$ Topical Conference on High-Temperature Plasma Diagnostics, San Diego, CA, USA, 19-22 April 2004 


\section{Description of the NPA Diagnostic}

The Neutral Particle Analyzer (NPA) diagnostic on NSTX utilizes a PPPLdesigned ElIB spectrometer shown in Fig. 1 that measures the energy spectra of $\mathrm{H}^{+}$and $\mathrm{D}^{+}$ion species simultaneously with a time resolution of $\sim 1 \mathrm{~ms}$ set by signal-to-noise levels. Details of this instrument were reported elsewhere [8] so only the salient features are given here. The calibrated energy range is $E=0.5-$ $150 \mathrm{keV}$ and the energy resolution varies from $\square E / E=7 \%$ at low $E$ to $\square E / E=3 \%$ at high E. The detector consists of a large area microchannel plate which is provided with two rectangular, semi-continuous active area strips, one coinciding with each of the mass rows for detection of $\mathrm{H}^{+}$and $\mathrm{D}^{+}$and each mass row has 39 energy channels. Detection of ions in the first and last pairs of energy channels in each mass column is blocked by a thin foil mask. These channels detect only neutrons and gammas and are used to correct the MCP signals for such background noise.

The NPA views across the co-injection paths of the three neutral beam lines on NSTX that inject at $R_{\mathrm{NB}}$ of $70 \mathrm{~cm}$ (source A), $60 \mathrm{~cm}$ (source B) and $50 \mathrm{~cm}$ (source $\mathrm{C}$ ) as shown in Fig. 2 and can be scanned horizontally over a sightline tangency range of $R_{\tan }=125 \mathrm{~cm}$ to $R_{\tan }=-75 \mathrm{~cm}$. Vertical scanning capability allows measurements to be made from the horizontal midplane through and angle of 26 degrees downward.

The source of the NPA signal in NSTX discharges is localized by the intersection of the sightline with the neutral beams. The insert in Fig. 3 shows TRANSP [9] calculation of the NPA emissivity for a deuterium ion energy of 60 $\mathrm{keV}$ and a sightline tangency radius of $\mathrm{R}_{\tan }=70 \mathrm{~cm}$ (blue curve) overlaid with the total beam neutral density for Source A (red curve) as a function of distance along the NPA sightline measured from the pivot point of the diagnostic (see Fig. 2). 
Also shown is the pitch angle variation along the sightline (black curve). As can be seen, the NPA emissivity is significantly localized due to charge exchange on the beam primary and halo neutrals. In this case, approximately $2 / 3$ of the integrated flux originates from the intersection of the NPA sightline with the NB region where ions are deposited on passing orbits. The remainder originates in the outboard regions of the plasma where ions are more likely to be deposited on trapped orbits. The pitch angle 'range' sampled by the NPA is obtained from this plot by noting the values of the pitch angle at the rising and falling edges of the beam neutral density curve. This process was repeated for Sources $B$ and $C$ and for other NPA tangency radii to obtain the curves shown in the main panel of Fig 3. Two features are to be noted. First, the pitch angle sampled by the NPA varies only weakly with the NB source. Second, the pitch angle range is such that the energetic ions sampled by the NPA are primarily passing particles. It must be noted that localization of the NPA signal weakens toward small values of $R_{\tan }$ due to attenuation of the beam neutrals.

The pulse counting data acquisition mode of the EllB spectrometer constrains the frequency response to $\sim 1 \mathrm{kHz}$ which limits usefulness of the diagnostic for measurements of fast MHD activity such as fishbones, sawteeth and reconnection events. To ameliorate this, a Compact Electrostatic Neutral Analyzer (CENA) that utilizes a carbon stripping foil and channeltron detectors operated in the analog mode [10] was installed on the straight through port of the EIIB NPA. This system is expected to extend measurements to the range of $10-$ $50 \mathrm{kHz}$.

\section{Ion Temperature Measurement}

In deuterium neutral beam heated deuterium plasmas, the NPA measures Maxwellian spectra of residual $\mathrm{H}^{+}$in the energy range of $1-15 \mathrm{keV}$ to obtain ion

\section{S. S. Medley, et al., Contributed paper to the $15^{\text {th }}$ Topical Conference on High-Temperature} Plasma Diagnostics, San Diego, CA, USA, 19-22 April 2004 
temperatures, $T_{i}[11]$. The deuterium thermal spectrum is useable only for energies up to $\sim 5 \mathrm{keV}$ because of spectrum contamination by deuterium beam slowing down ions. In Ohmic plasmas, the deuterium majority species is used for NPA $T_{i}$ measurements, an example of which is shown in Fig. 4 . In this case, 20 ms neutral beam pulses were injected to facilitate $T_{i}$ measurements using Charge Exchange Recombination Spectroscopy (CHERS). Details of CHERS and other diagnostics on NSTX can be found in [12]. The insert shows a typical NPA thermal ion spectrum obtained with a time resolution of $5 \mathrm{~ms}$. In the absence of NB blips, the passive NPA $T_{i}$ measurements underestimate the central ion temperature by $\sim 100 \mathrm{eV}$ or $\sim 15 \%$, this being due to attenuation of the charge exchange efflux from the core due to plasma opacity. During the NB blips, the active NPA and CHERS measurements of $T_{i}(0)$ are in good agreement. In NB heated discharges, good agreement between CHERS and NPA minority $\mathrm{H}^{+} \mathrm{T}_{\mathrm{i}}(0)$ is also observed for electron densities up to $\mathrm{n}_{\mathrm{e}}(0) \sim 4 \times 10^{13} \mathrm{~cm}^{-3}$. At higher densities, plasma opacity again interferes with the NPA measurements and it is necessary to correct for this effect with code modeling [11].

\section{Neutral Beam Energy Distribution and Profile}

The NPS measures $\mathrm{D}^{+}$energetic ion spectra produced by injection of neutral beams into deuterium plasmas, including effects of MHD activity on the energetic ion distribution $[13,14]$. The horizontal scanning capability for the NPA over a sightline tangency range of $R_{\mathrm{tan}}=125 \mathrm{~cm}$ to $R_{\mathrm{tan}}=-75 \mathrm{~cm}$ has enabled measurement of the anisotropic energy distribution of the beam ions, as illustrated in Fig. 5. This spectrum was derived from energy distributions measured on a shot-to-shot basis over eleven semi-reproducible discharges in the discharge range of SN108831 - SN108847. For these L-mode discharges, $I_{\mathrm{p}}=0.85 \mathrm{MA}, B_{\mathrm{T}}=0.58 \mathrm{~T}$ and source $\mathrm{B}$ was injected with $E_{\mathrm{b}}=80 \mathrm{keV}, P_{\mathrm{NB}}=1.7$

\section{S. S. Medley, et al., Contributed paper to the $15^{\text {th }}$ Topical Conference on High-Temperature} Plasma Diagnostics, San Diego, CA, USA, 19-22 April 2004 
MW starting in the current ramp up from $t=100-200 \mathrm{~ms}$ during which time the line average electron density varied from $n_{\mathrm{e}}=1.2-2.0 \times 10^{19} \mathrm{~m}^{-3}$. The electron temperature from Multi-Pulse Thomson Scattering varied from $T_{\mathrm{e}}(0)=0.4-0.7$ $\mathrm{keV}$ and the ion temperature from Charge Exchange Recombination Spectroscopy varied from $T_{\mathrm{i}}(0)=0.3-1.0 \mathrm{keV}$.

The spectrum peaks around the beam injection tangency radius, $R_{\mathrm{NB}}=59$ $\mathrm{cm}$, and the full, half and third beam energy components are evident. The spectrum is highly anisotropic with the ion population depleting with decreasing NPA tangency radius. This occurs because decreasing tangency radius corresponds to decreasing pitch angle and beam deposition on trapped orbits whereas the co-injected tangential NB deposits ions primarily on passing orbits with pitch angle approaching unity. Evidence of spectrum fill below the critical energy, $E_{\text {crit }} \sim 15 \mathrm{keV}$ due to pitch angle scattering can be seen.

An example of the elevation NB profile obtained by vertical scanning of the NPA in a dedicated NSTX experiment with highly reproducible discharges is shown in Fig. 6. The data set spanned the shot range SN11517-532 and consisted of L-mode discharges with $I_{\mathrm{p}}=0.8 \mathrm{MA}, B_{\mathrm{T}}=0.43 \mathrm{~T}$ and line average electron density varying from $n_{\mathrm{e}}=1.0-4.0 \times 10^{13} \mathrm{~cm}^{-3}$ during the current flattop interval of $t \sim 150-500 \mathrm{~ms}$. NB sources $A, B$ and $C$ having full energies in the range of $80-90 \mathrm{keV}$ were injected sequentially with $\sim 100 \mathrm{~ms}$ pulse lengths separated by $\sim 20$ beam off intervals. The full and half energy 'peaks' are evident in Fig. 6. The e-folding width of the elevation profile is $\sim 15$ degrees which translates to $\sim 25 \mathrm{~cm}$. This is consistent with the expected beam profile from the $40 \mathrm{~cm}$ high beam ion source grids situated on the NSTX mid-plane. Further analysis of this data is beyond the scope of this paper and will be presented in another venue.

Other experiments conducted on NSTX support classical behavior of energetic ions in discharges exhibiting benign MHD activity. The confinement of

\section{S. S. Medley, et al., Contributed paper to the $15^{\text {th }}$ Topical Conference on High-Temperature} Plasma Diagnostics, San Diego, CA, USA, 19-22 April 2004 
dilute populations of beam ion in NSTX was investigated by injecting short $\sim 3 \mathrm{~ms}$ pulses of $80 \mathrm{keV}$ deuterium neutrals [15]. The neutron decay rate versus time after the beam blip ends was compared with the decay rate expected due to collisional slowing down of the beam ions effected via TRANSP modeling. Similarly, evolution of the energetic ion spectra measured by the neutral particle analyzer was compared with classical slowing down expectations. The temporal evolutions of the neutron yield and neutral particle signals were found to be consistent with Coulomb scattering rates, implying an effective beam-ion confinement time $>100 \mathrm{~ms}$. 


\section{References}

[1] M. Ono, et al., 2001 Nucl. Fusion 411435.

[2] Y.-K. M. Peng and D. J. Strickler, 1986 Nucl. Fusion 26769.

[3] J. E. Menard, et al., 2003 Nucl. Fusion 43330.

[4] E.J. Synakowski, et al., 2003 Nucl. Fusion 431653.

[5] D. A. Gates, et al., 2003 Phys. Plasmas 101659.

[6] R. Mangi, et al., 2003 Plasma Phys. Control. Fusion 45657.

[7] R. Mangi, et al., 2003 Nucl. Fusion 43969.

[8] S. S. Medley and A. L. Roquemore, 1998 Rev. Sci. Instrum. 692651.

[9] J. Onega, M. Evrard, D. McCune, 1998 Trans. of Fusion Technology 33182.

[10] P. Biersdorfer, A. L. Roquemore and R. Kaita, 1987 Rev. Sci. Instrum. 58 2092.

[11] S. S. Medley, R. E. Bell, M. P. Petrov, A. L. Roquemore and E. V. Suvorkin, 2003 Rev. Sci. Instrum. 741869.

[12] D. W. Johnson et al., 2003 Plasma Phys. Control. Fusion 451975.

[13] E. D. Fredrickson, C. Z. Cheng, D. Darrow, G. Fu, N. N. Gorelenkov, G. Kramer, S. S. Medley, J. Menard, and A. L. Roquemore, 2003 Phys. Plasmas 102852.

[14] S. S. Medley, et al., "MHD-induced Energetic lon Loss during H-mode Discharges in the National Spherical Torus Experiment(NSTX)", 2004 Princeton Plasma Physics Report, PPPL-3931.

[15] W. W. Heidbrink, M. Miah, D. Darrow, B. LeBlanc, S. S. Medley, A. L. Roquemore and F. E. Cecil, 2003 Nucl. Fusion 43883. 


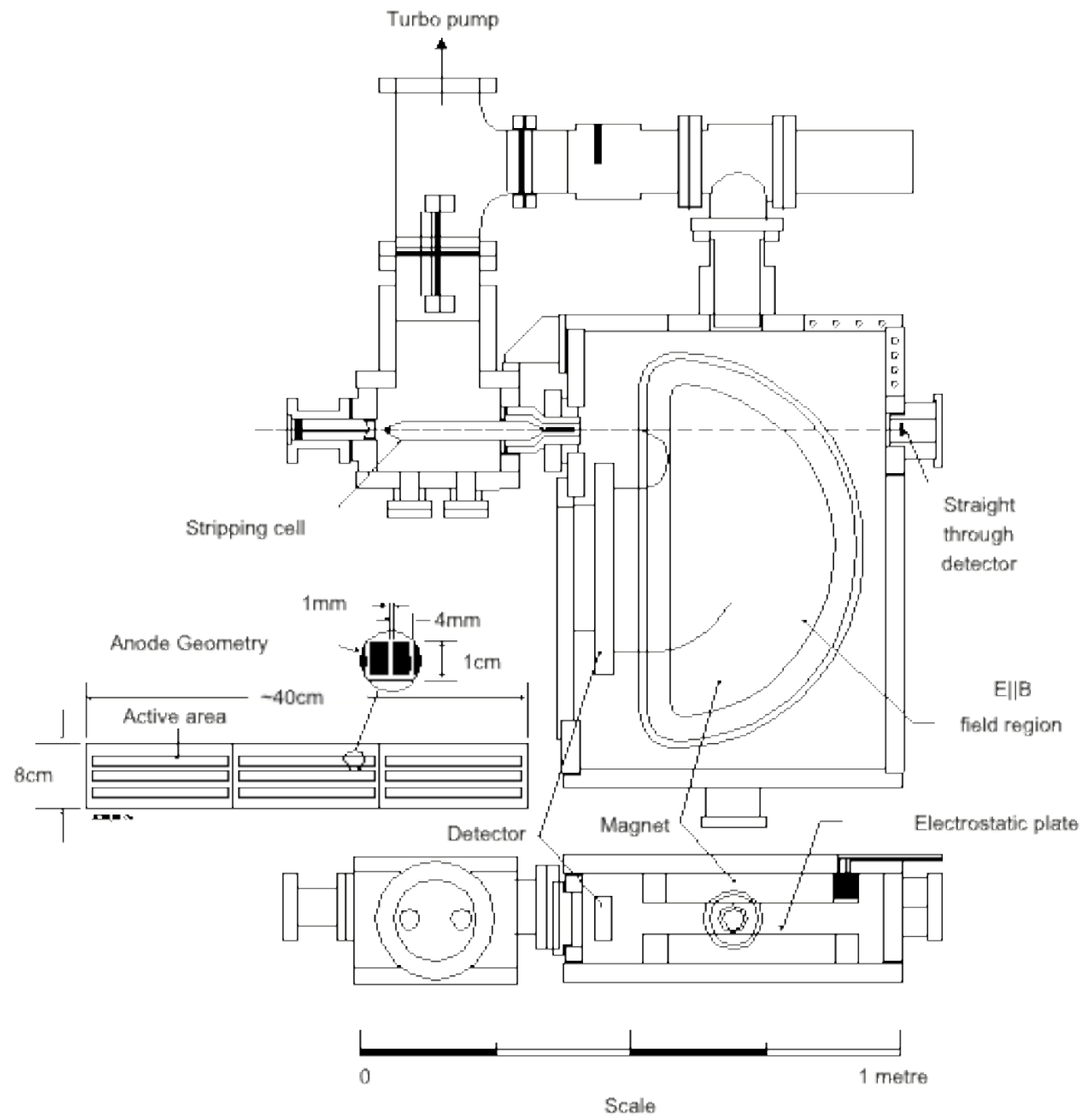

Figure 1. Schematic of the NSTX EIIB spectrometer showing plan and elevation cross section of the apparatus with the insert (not to scale) illustrating the geometry of the microchannel plate detector. The smaller chamber houses a $25 \mathrm{~cm}$ long stripping cell typically operated a $1-3 \mathrm{mTorr}$ of helium. The main chamber that contains the field region and the detector is approximately $90 \mathrm{~cm}$ long by $60 \mathrm{~cm}$ wide by $23 \mathrm{~cm}$ deep.

S. S. Medley, et al., Contributed paper to the $15^{\text {th }}$ Topical Conference on High-Temperature Plasma Diagnostics, San Diego, CA, USA, 19-22 April 2004 


\section{Source C: $\mathrm{R}_{\mathrm{NB}}=48.7 \mathrm{~cm}$}

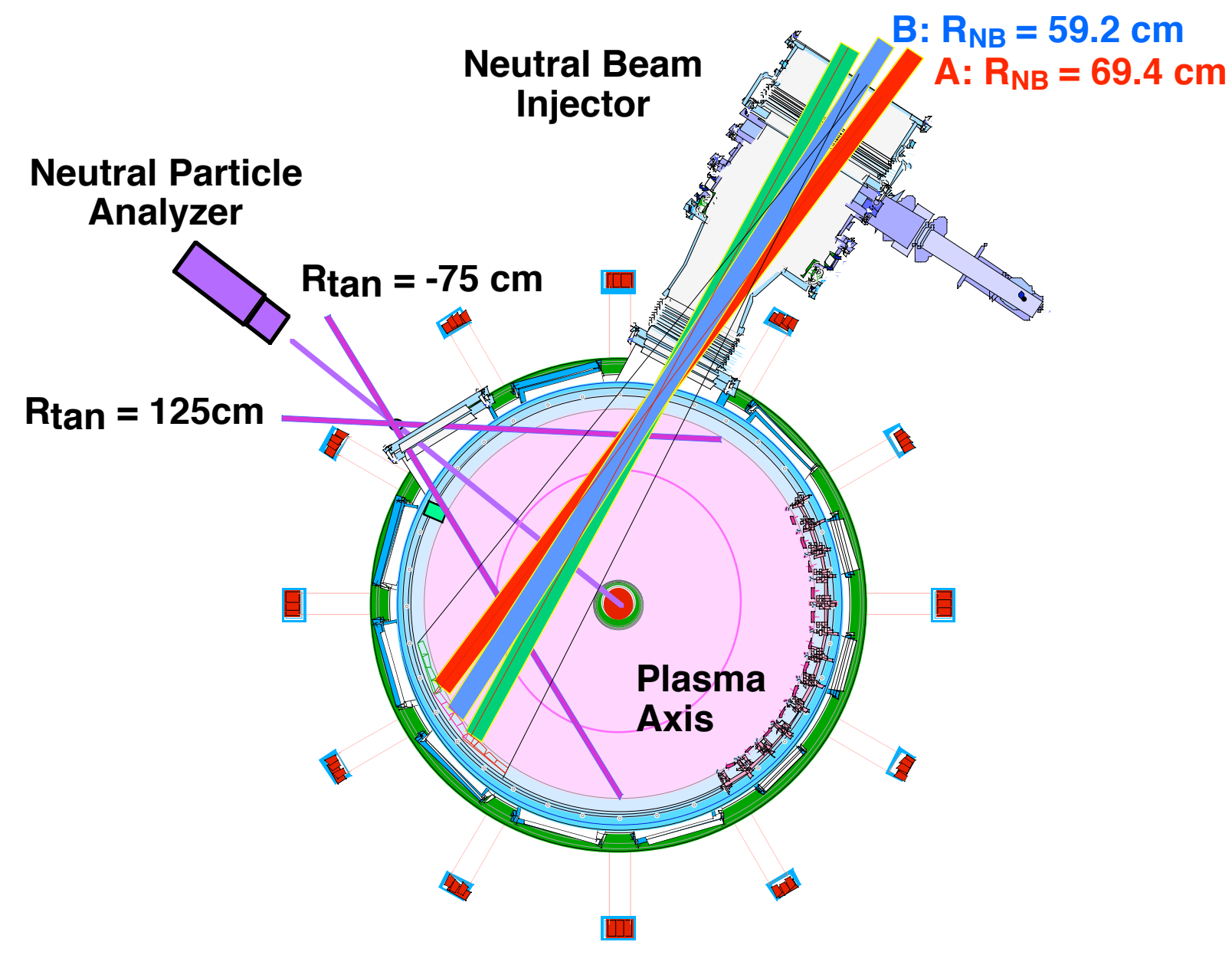

Figure 2. The Neutral Particle Analyzer (NPA) on NSTX views across the three neutral beam injection sources and can be scanned over a wide range of sightline tangency radii, $R_{\text {tan }}$, on a shot-to-shot basis. $R_{\text {tan }}$, is the perpendicular distance between the machine center and the NPA sightline.

S. S. Medley, et al., Contributed paper to the $15^{\text {th }}$ Topical Conference on High-Temperature Plasma Diagnostics, San Diego, CA, USA, 19-22 April 2004 


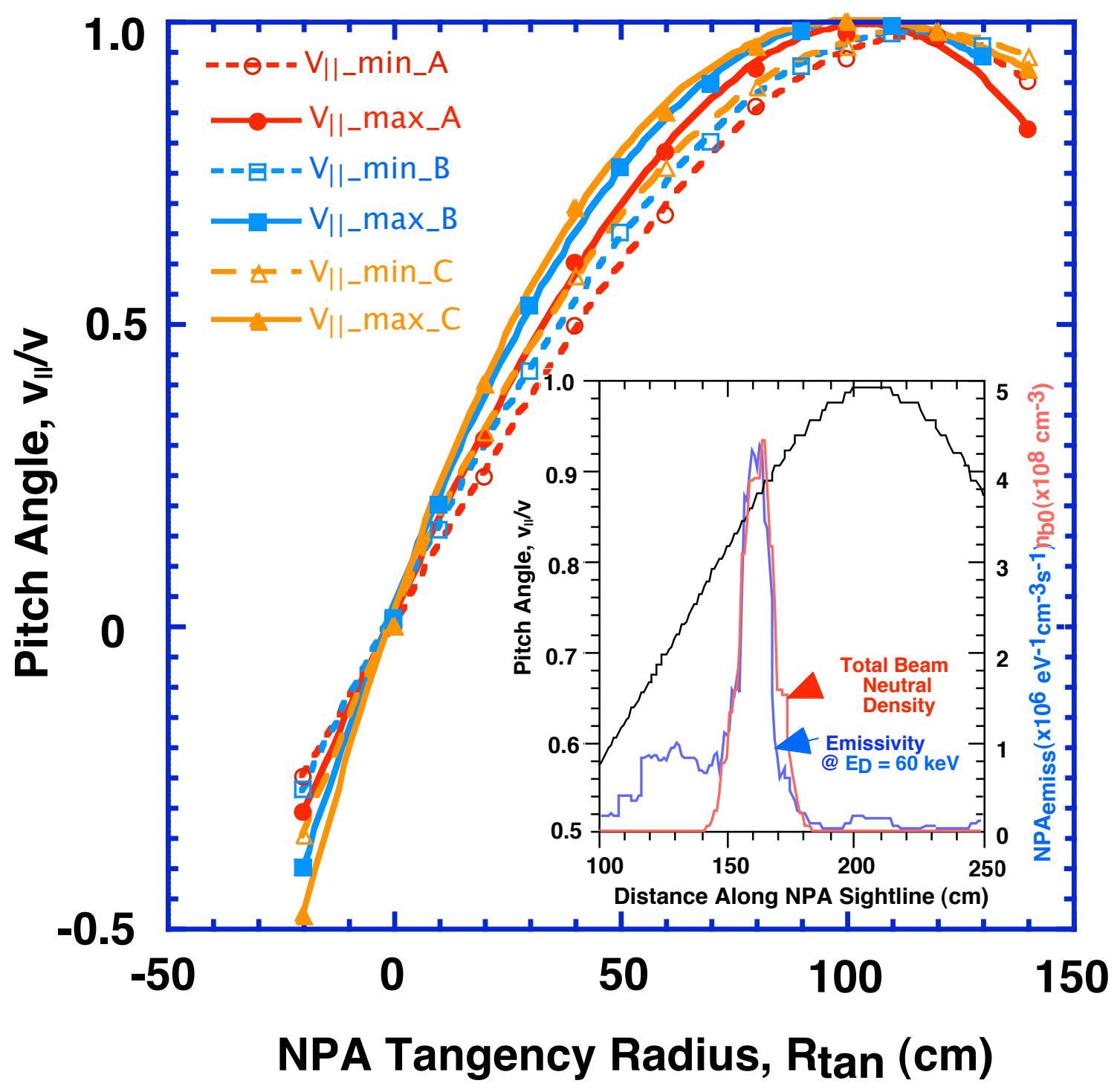

Figure 3. The NPA signal is localized to a significant extent by beam neutrals. As shown in the insert, approximately $2 / 3$ of the integrated flux originates from the NPA/NB intersection region where ions are deposited on passing orbits. The remainder originates in the outboard regions of the plasma where ions are more likely to be deposited on trapped orbits. The ratio of beam localized passing flux to peripheral trapped flux viewed by the NPA decreases with increasing NPA tangency radius. Shown in the main panel is the variation of pitch angle sampled by the NPA as a function of viewing tangency radius. For a large part of the NPA scan range, $R_{\text {tan }}, \quad 30-120 \mathrm{~cm}$, the diagnostic signal is weighted towards passing ions.

S. S. Medley, et al., Contributed paper to the $15^{\text {th }}$ Topical Conference on High-Temperature Plasma Diagnostics, San Diego, CA, USA, 19-22 April 2004 


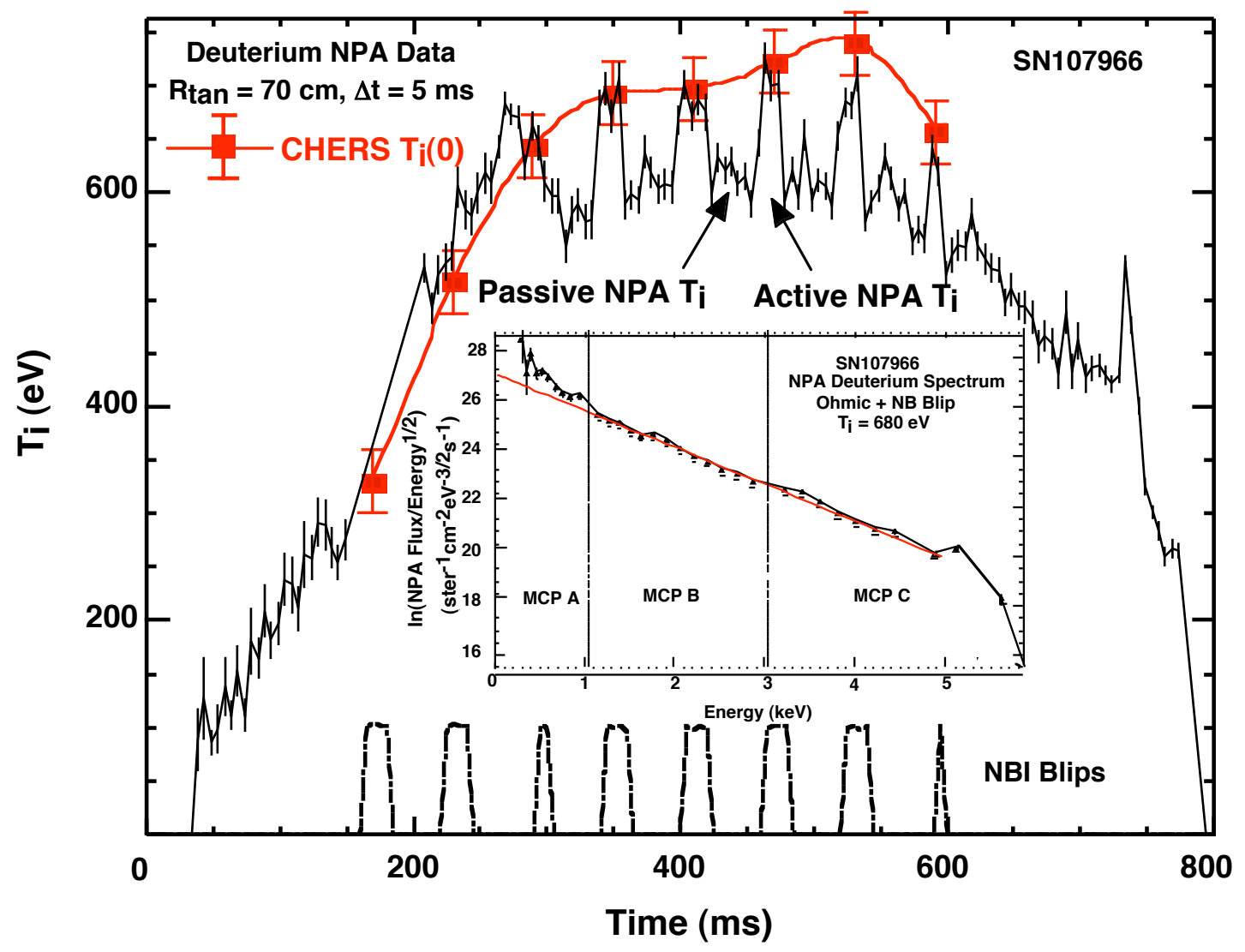

Figure 4. NPA passive and active measurements of the deuterium ion temperature in an Ohmic discharge are shown. During the NB "blips" good agreement is observed between the NPA and CHERS measurements. A typical deuterium thermal spectrum is shown in the insert. The dashed vertical lines demark the three microchannel plate sections constituting the NPA detector.

S. S. Medley, et al., Contributed paper to the $15^{\text {th }}$ Topical Conference on High-Temperature Plasma Diagnostics, San Diego, CA, USA, 19-22 April 2004 


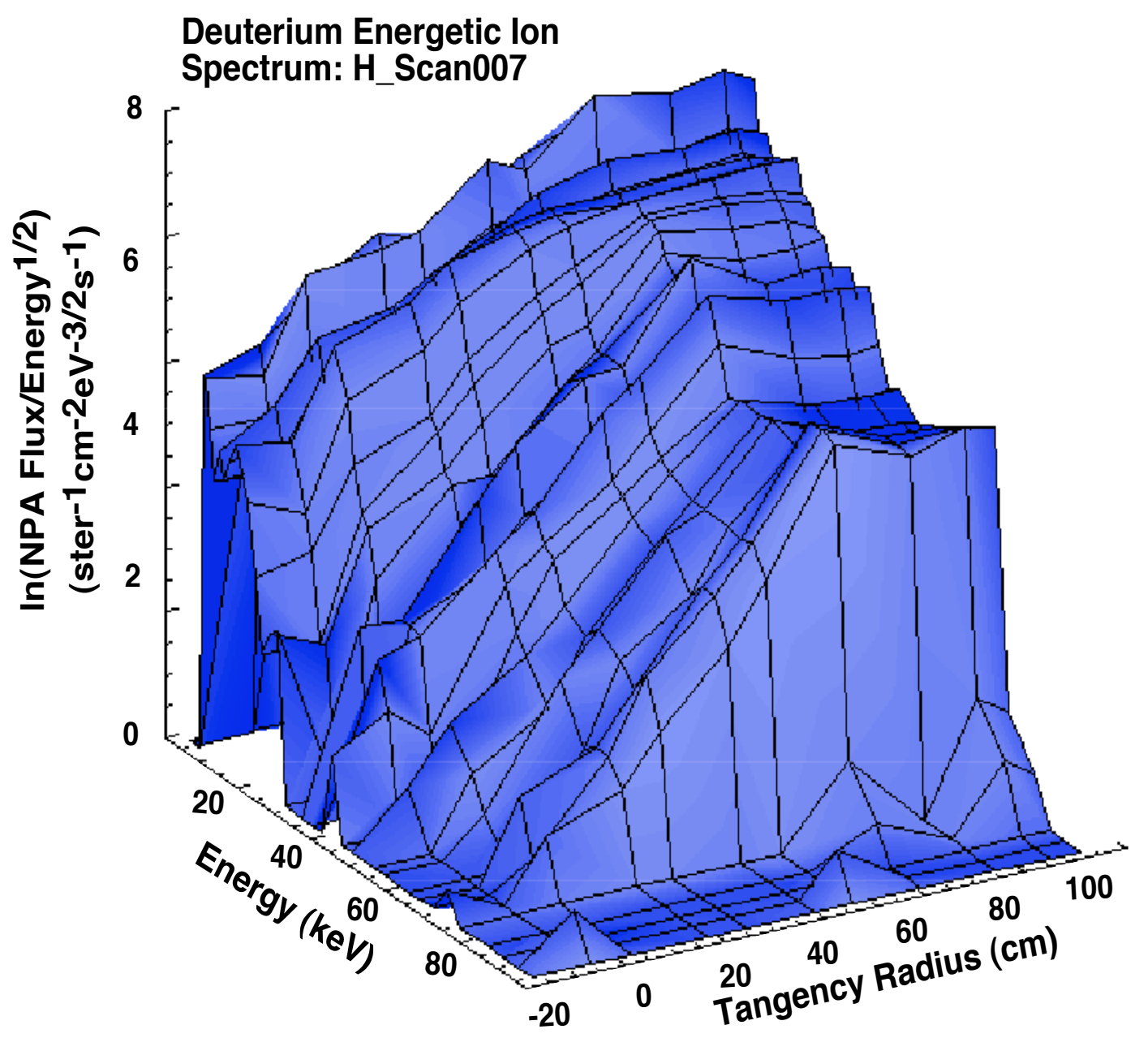

Figure 5. Shown is the NPA measurement of the NB ion distribution versus energy and tangency radius or 'pitch angle' for source $B$. The spectrum peaks around the beam injection tangency radius, $R_{N B}=59 \mathrm{~cm}$, and the full, half and third beam energy components are evident. The spectrum is highly anisotropic with the ion population depleting with decreasing NPA tangency radius, which corresponds to decreasing pitch angle. Some evidence of spectrum 'fill' below the critical energy of $\sim 15 \mathrm{keV}$ as a result of $90^{\circ}$ pitch angle scattering can be inferred.

S. S. Medley, et al., Contributed paper to the $15^{\text {th }}$ Topical Conference on High-Temperature Plasma Diagnostics, San Diego, CA, USA, 19-22 April 2004 


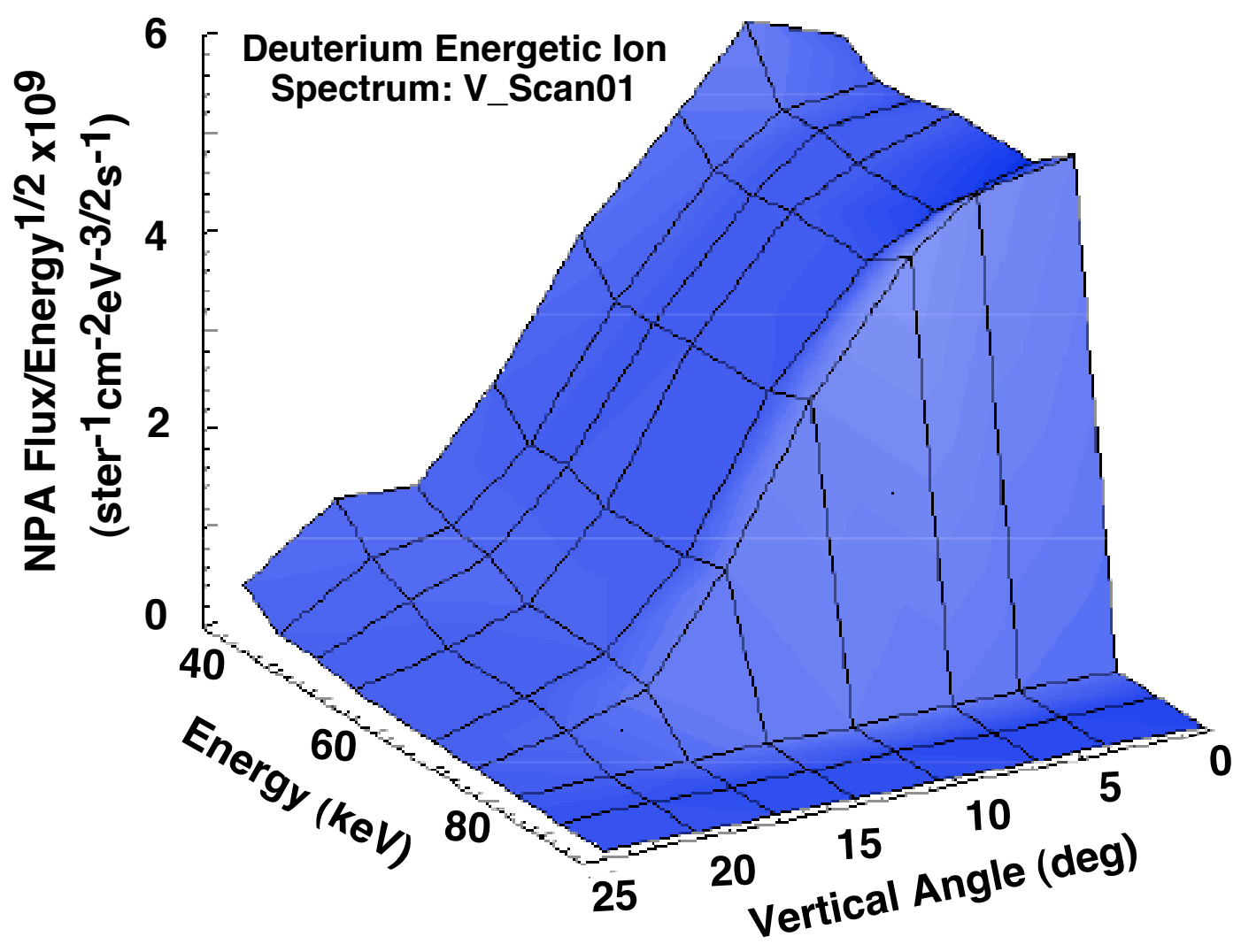

Figure 6. Shown is the NPA measurement of the NB elevation profile versus beam energy and vertical scan angle obtained at $R_{\text {tan }}=80 \mathrm{~cm}$ revealing the spatial distribution of the injected neutral beam Source $A$ below the midplane.

S. S. Medley, et al., Contributed paper to the $15^{\text {th }}$ Topical Conference on High-Temperature Plasma Diagnostics, San Diego, CA, USA, 19-22 April 2004 


\section{External Distribution}

Plasma Research Laboratory, Australian National University, Australia

Professor I.R. Jones, Flinders University, Australia

Professor João Canalle, Instituto de Fisica DEQ/IF - UERJ, Brazil

Mr. Gerson O. Ludwig, Instituto Nacional de Pesquisas, Brazil

Dr. P.H. Sakanaka, Instituto Fisica, Brazil

The Librarian, Culham Laboratory, England

Mrs. S.A. Hutchinson, JET Library, England

Professor M.N. Bussac, Ecole Polytechnique, France

Librarian, Max-Planck-Institut für Plasmaphysik, Germany

Jolan Moldvai, Reports Library, Hungarian Academy of Sciences, Central Research Institute for Physics, Hungary

Dr. P. Kaw, Institute for Plasma Research, India

Ms. P.J. Pathak, Librarian, Institute for Plasma Research, India

Ms. Clelia De Palo, Associazione EURATOM-ENEA, Italy

Dr. G. Grosso, Instituto di Fisica del Plasma, Italy

Librarian, Naka Fusion Research Establishment, JAERI, Japan

Library, Laboratory for Complex Energy Processes, Institute for Advanced Study, Kyoto University, Japan

Research Information Center, National Institute for Fusion Science, Japan

Dr. O. Mitarai, Kyushu Tokai University, Japan

Dr. Jiangang Li, Institute of Plasma Physics, Chinese Academy of Sciences, People's Republic of China

Professor Yuping Huo, School of Physical Science and Technology, People's Republic of China

Library, Academia Sinica, Institute of Plasma Physics, People's Republic of China

Librarian, Institute of Physics, Chinese Academy of Sciences, People's Republic of China

Dr. S. Mirnov, TRINITI, Troitsk, Russian Federation, Russia

Dr. V.S. Strelkov, Kurchatov Institute, Russian Federation, Russia

Professor Peter Lukac, Katedra Fyziky Plazmy MFF UK, Mlynska dolina F-2, Komenskeho Univerzita, SK-842 15 Bratislava, Slovakia

Dr. G.S. Lee, Korea Basic Science Institute, South Korea

Institute for Plasma Research, University of Maryland, USA

Librarian, Fusion Energy Division, Oak Ridge National Laboratory, USA

Librarian, Institute of Fusion Studies, University of Texas, USA

Librarian, Magnetic Fusion Program, Lawrence Livermore National Laboratory, USA

Library, General Atomics, USA

Plasma Physics Group, Fusion Energy Research Program, University of California at San Diego, USA

Plasma Physics Library, Columbia University, USA

Alkesh Punjabi, Center for Fusion Research and Training, Hampton University, USA

Dr. W.M. Stacey, Fusion Research Center, Georgia Institute of Technology, USA

Dr. John Willis, U.S. Department of Energy, Office of Fusion Energy Sciences, USA

Mr. Paul H. Wright, Indianapolis, Indiana, USA 
The Princeton Plasma Physics Laboratory is operated by Princeton University under contract with the U.S. Department of Energy.

\author{
Information Services \\ Princeton Plasma Physics Laboratory \\ P.O. Box 451 \\ Princeton, NJ 08543
}

Phone: 609-243-2750

Fax: 609-243-2751

e-mail: pppl_info@pppl.gov

Internet Address: http://www.pppl.gov 